\title{
"I Need to Start Listening to What my Body Is Telling Me.": Does Mindfulness-Based Cognitive Therapy Help People with Chronic Fatigue Syndrome?
}

\author{
Bridie O'Dowd ${ }^{1}$ (D) $\cdot$ Gemma M. Griffith ${ }^{1}$ \\ Received: 2 March 2020 /Revised: 2 March 2020 / Accepted: 3 June 2020 / \\ Published online: 16 July 2020 \\ (C) The Author(s) 2020
}

\begin{abstract}
Mindfulness-Based Cognitive Therapy (MBCT) was lightly adapted for participants diagnosed with chronic fatigue syndrome (CFS). The aim of the study was to explore participants' experiences of the MBCT course, with a particular focus on how they applied MBCT to living with and coping with the symptoms of CFS. Nine participants with CFS who completed the MBCT course were interviewed using semi-structured interview methods. Inductive thematic analysis, a methodology designed to generate themes from the "bottom up," was used. Four superordinate themes were generated from the data: (1) awareness of unhelpful behavioral patterns associated with CFS, (2) benefits of group solidarity, (3) use of mindfulness tools to facilitate shifts in behavioral patterns, and (4) a sense of change and agency. Participants became aware of three specific transformative changes that contributed to a more skillful way of living with CFS: development of acceptance, improved self-care and self-compassion, and reduction in heightened stress response. MBCT appears to enable people with CFS to actively work with their symptoms, and make transformative changes in their behavioral patterns, resulting in benefits to well-being.
\end{abstract}

Keywords Mindfulness -based cognitive therapy · Cognitive behavioral therapy · Chronic fatigue syndrome $\cdot$ Qualitative $\cdot$ Mindfulness

Chronic fatigue syndrome (CFS) is a poorly understood condition characterized by a minimum of 6 months of persistent, medically unexplained, debilitating fatigue, not caused by on-going exertion or relieved by rest, and which substantially interferes with activities of daily living (Centers for Disease Control and Prevention 2014; Fukuda et al. 1994). The syndrome,

Gemma M. Griffith

g.m.griffith@bangor.ac.uk

1 Centre for Mindfulness Research and Practice, School of Psychology, Bangor University, Brigantia Building, Penrallt Road, Bangor LL57 2AS, Wales 
frequently triggered by a viral infection, often has a heterogeneous presentation, an unclear etiology, which may be of genetic, immunological, endocrinological, and/or neurological origin, and is associated with premorbid psychological personality traits (Carruthers et al. 2003).

Primary care practitioners are often reluctant to diagnose CFS, due to a poor knowledge about the condition and a lack of a clear management plan (Chew-Graham et al. 2010). As a result, patients with CFS frequently experience misunderstanding, judgment, and skepticism around their illness from both healthcare providers and their own social networks. This judgment is frequently perceived as an implication that they are malingering, lazy, or even lying about the severity of their symptoms ( $̊$ sbring and Närvänen 2002; Larun and Malterud 2007).

The experience of stigma from healthcare providers and their own social networks (Dickson et al. 2008; Larun and Malterud 2007) powerfully jars with a characteristic set of personality traits typically found within the CFS population: perfectionism, a conscientious and driven working style, and self-criticism (Asbring 2001; Whitehead 2006). These traits seem to serve as both etiological factors and on-going drivers of the condition as people with CFS make great efforts to maintain their premorbid active status, which often results in exhaustion (Hambrook et al. 2011; Van Houdenhove and Luyten 2008).

Moss-Morris and Chalder (2003), Larun and Malterud (2007), and Van Houdenhove and Luyten (2008) found that most people with CFS had deeply held beliefs that their condition was purely physical in etiology and as a result were strongly resistant to suggestions of any emotional or psychological component to CFS. These beliefs correlated with poorer outcomes in terms of on-going fatigue, impairment, resistance to adjustment, and slower recovery. In contrast, people with CFS who are willing to accept some degree of psychological etiology were then able to take steps to actively manage their condition, such as attempting realistic activity within the constraints of their fatigue, and this is associated with improvement in CFS symptoms (Heijmans 1998; Moss-Morris and Chalder 2003).

Stress appears to be part of the mechanism of origin and perpetuation of CFS, and may explain some of the symptomatology (Van Houdenhove and Luyten 2008). Luyten et al. (2011) and Clements et al. (1997) found that half of their participants with CFS acknowledged that stress, albeit as an external experience and therefore out of their control and responsibility, was an etiological factor contributing to their CFS symptoms. People with CFS have a tendency to over-think, especially with regard to their CFS symptomatology, which can relate to strong beliefs that increased activity would have highly negative effects on their CFS. This can lead to an avoidant, disengaged, and passive attitude to recovery, particularly around kinesiophobia, a fear of movement (Moss-Morris et al. 2005; Van Houdenhove and Luyten 2008).

There appears to be a typical behavioral pattern associated with people suffering from CFS. Over-activity geared towards striving to maintain a premorbid high-functioning status, followed by excessive rest periods driven by a fear that any activity could aggravate symptoms seems to underpin, perpetuate, and aggravate CFS (Åsbring and Närvänen 2002; Van Houdenhove and Luyten 2008; Whitehead 2006). This is the cognitive theory of CFS (Surawy et al. 1995). This Cognitive Behavioral model, sometimes known as the "boom and bust" cycle, clearly provides openings for the application of Cognitive Behavioral Therapy (CBT), which can be utilised to alter the beliefs, cognitions, and behavior that perpetuate CFS.

Several quantitative studies report beneficial effects of CBT for people with CFS: reduced fatigue, return to daily activities and work, and improved quality of life and mood (Chambers 
et al. 2006; Knoop et al. 2007). These improvements may be due to CBT increasing participants' awareness of self-perpetuating illness-related cognitions such as perfectionist tendencies, alongside encouragement of an active rather than passive coping model. CBT may also help to alter the maladaptive and illness-perpetuating oscillation between extreme over-exertion and extreme avoidance of exertion (Sharpe et al. 1996; Surawy et al. 1995; Wiborg et al. 2010).

Given the characteristics of CFS, training in mindfulness, characterized as "intentional selfregulation of attention from moment to moment" (Kabat-Zinn 1982, p. 34), has the capacity to further increase self-awareness with the potential to augment the benefits of CBT. A recent cross-sectional study reported that in the general population, higher fatigue was associated with lower dispositional mindfulness, and the authors reported that MBPs may have the potential to alleviate fatigue among general populations (Whitaker et al. 2019).

There is emerging research interest in adapting Mindfulness-Based Programmes (MBPs) for people with CFS, albeit the area is in its infancy. We could find just three quantitative studies exploring MBPs for people with CFS. Surawy et al. (2005) assessed three exploratory studies which evaluated the benefits of Mindfulness-Based Cognitive Therapy (MBCT) and Mindfulness-Based Stress Reduction (MBSR) in people with CFS and reported improvements in levels of anxiety (effect size 0.84-1.32), subjective experience of fatigue (effect size 0.841.6), and enhanced quality of life (effect size 0.68-0.86). Sampalli et al. (2009) explored the changes in symptomatology of CFS patients after attending an MBSR course, and found statistically significant improvements in global scores of somatization, depression, and anxiety. Rimes and Wingrove (2013), in a study with participants still experiencing excessive fatigue after CBT, additionally found statistically significant improvements in unhelpful cognitions $(p=.012)$ and all-or-nothing behavior $(p=.017)$ after attending an MBCT course.

The question of the mechanism of how the MBP led to the observed improvements was postulated in the three studies, but not explored directly. Each research team attributed these improvements to a similar mechanism that mindfulness, through its cultivation of awareness, increased consciousness of maladaptive patterns of thinking and behavior (Rimes and Wingrove 2013; Sampalli et al. 2009; Surawy et al. 2005). This in turn appeared to lead to improved regulation in the form of response and relationship to unhelpful thought processes, both the over-focus on illness-related CFS symptomatology and hyper-vigilant, catastrophizing thinking. In addition, researchers proposed a potential shift in perspective towards acceptance and adaptation. However, the mechanisms proposed are putative; to date there are no studies that examine the mechanisms of MBPs in this population.

The aim of the study was, to explore, the participants' experiences of the MBCT course, with a particular focus on how they applied MBCT to living with the symptoms of CFS, and the putative mechanisms by which MBCT might help people with CFS manage their symptomology.

\section{Method}

\section{Participants}

Nine participants were interviewed. Criteria for inclusion were as follows: (1) meeting the criteria for CFS (Centre for Centers for Disease Control and Prevention 2014; Fukuda et al. 1994), (2) meeting "case-ness" for CFS on the Chalder Fatigue Scale (Chalder et al. 1993), (3) 
understanding spoken and written English, and (4) being over 18 years old. Exclusion criteria were the following: potentially serious physical or mental health comorbidity (i.e., suicidal ideation, psychosis, substance abuse, post-traumatic stress disorder, active depression), and inability to attend at least four of the 8-week, 2-h MBCT sessions.

Table 1 shows participant demographic information. The Chalder Fatigue Scale (Chalder et al. 1993), with "case-ness for CFS" being 24 on a possible 33 point-scale, ranged from 25 to 33 (mean 29.8) in the current sample. This figure is suggestive of a relatively high degree of morbidity in the group. The length of time from the development of disabling symptoms (rather than length of time from diagnosis since diagnosis is frequently delayed) ranged from 1 year to 20 years (mean 6.5 years).

\section{Procedure}

Ethical approval was gained from Bangor University and the NHS Research and Ethics Committee. This study was conducted in the National Health Service (NHS) Centre for Integrative Care (NHS CIC). All patients with CFS who attended their regular clinical appointments during the recruitment period were given a study information leaflet at the end of their appointment.

If the potential participants wished to find out more about the study, they contacted the researcher via email or telephone, the researcher checked to see if they met the broad inclusion criteria, and if they did, then a full assessment appointment was arranged and the information sheet and consent form sent to the participant via post or email. Assessment appointments were held within the NHS CIC unit or by telephone, lasted around $60 \mathrm{~min}$, and gathered demographic information, confirmed study inclusion and exclusion criteria, outlined the MBCT course, and offered an opportunity to experience a short mindfulness practice.

Twelve participants consented to take part in the study. They were enrolled on the MBCT course, which began with an orientation session, followed by the eight-week MBCT course. Three participants dropped out of the course, two after the first week, and were thus not interviewed. Two participants said attending the course each week was too draining and one also reported that lying and sitting for the meditation practices was painful. The third felt they had already found successful ways of coping with their condition.

All participants were interviewed within 2 weeks of the completion of the MBCT course. The interviews were held face to face within the NHS CIC unit, or over the phone, lasted between 45 and 90 minutes and were conducted by a research assistant. The interview was

Table 1 Participant demographics

\begin{tabular}{llllll}
\hline Pseudonym & Age & Gender & $\begin{array}{l}\text { Chalder Fatigue } \\
\text { Scale Score }\end{array}$ & Employment status & $\begin{array}{l}\text { Number of years } \\
\text { of symptoms }\end{array}$ \\
\hline Beth & 51 & Female & 32 & Working & 9 \\
Carol & 57 & Female & 30 & Not working & 3 \\
Emma & 46 & Female & 32 & Not working & 20 \\
Flora & 45 & Female & 29 & Working & 6 \\
Gillian & 31 & Female & 29 & Not working & 6 \\
Hannah & 38 & Female & 30 & Working & 5 \\
Iain & 40 & Male & 26 & Not working & 3 \\
Kath & 49 & Female & 30 & Working & 1 \\
Lynn & 53 & Female & 31 & Not working & 6 \\
\hline
\end{tabular}


semi-structured to allow freedom for the participants to describe their experience in their own way, with questions such as: "How did you find attending a mindfulness course?", "How did you find being in a group of people who all had CFS?", and "Were there any key moments or discoveries for you on the course?" All participant names have been replaced by pseudonyms.

The eight-week MBCT course was originally designed for people with depression (Segal et al. 2013), and the MBCT was taught following the recommended curriculum including the meditations and suggested home practice. However, the first author incorporated a few adaptations to tailor the course to the particular vulnerabilities of CFS participants (Crane et al. 2017). The psycho-educational elements were made specific to CFS rather than depression, and the option of shorter 20-min versions of the home practice meditations were offered. These adaptations were undertaken after discussion and supervision sessions with two mindfulness teachers who have been involved in adapting the MBCT course to the specific vulnerabilities of CFS participants. The MBCT course was taught by the first author who has been teaching MBPs for 8 years and has been assessed as "proficient" on the Mindfulnessbased interventions:Teaching assessment criteria (MBI:TAC) (Crane et al. 2013).

\section{Data Analysis}

The Journal Article Reporting Standards for Qualitative Research (JARS-Qual; Levitt et al. 2018) was adhered to throughout the data collection and analysis, which outlines key standards for qualitative researchers. Inductive thematic analysis was chosen to analyze the data, because little is known about how people with CFS have experienced an MBP. An inductive methodin which the researchers generate the analysis from the data "bottom up," and is not shaped by extant theory (Braun and Clarke 2013) was deemed most appropriate to the research aims. Inductive thematic analysis, used for recognizing patterning and meaning in qualitative data, comprises of six stages (Braun and Clarke 2006): (1) detailed transcription of the data, in order to identify patterns, (2) generating codes distilled from the patterns within the data, (3) a systematic exploration of the codes to form the basis of themes and sub-themes, (4) the themes are refined and distilled, (5) the themes are named and organized in a coherent way, (6) the themes are used to construct of framework on which the analysis is based. The first author analyzed the data following the guidelines by Braun and Clarke (2006, 2013), and received academic supervision from the second author throughout the analysis.

It acknowledged in inductive thematic analysis that the analysis is inherently shaped by the researcher's subjective views (Braun and Clarke 2013; Willig 2013), and thus steps must be taken to minimize this in order maintain methodological integrity. To adhere to the ethic of transparency of reporting in qualitative research (Levitt et al. 2018), it is important to acknowledge four potential sources of author bias in this study. First, the first author taught the MBCT course. Second, as the first author conducted the transcription of the data, the voices of the participants were recognizable by the researcher. Third, the researcher had taught the MBCT curriculum to many people with CFS before and may have anticipated "typical" outcomes in this population and therefore been blinkered to more unusual or unique themes emerging. Fourth, both authors are MBP teachers and have their own personal mindfulness practice. The authors made efforts to remain open to what the data held, to ensure - as far as possible - the inductive nature of the analysis. Potential bias was fully acknowledged and worked with by using a reflexive diary throughout the analysis process. For example, both authors had a prior keen interest in group dynamics in MBP classes, and were perhaps primed to notice and pull out findings on this theme in the data (Griffith et al., 2019). This was explored 
in the reflexive diary, and discussed during academic supervision. It was decided that - even though the authors may have anticipated a theme about the group process emerging - there was clearly enough data that robustly demonstrated the theme of group solidarity. The data for "group solidarity" was drawn from multiple participants, and was thus rich enough suggest that it would have emerged as a theme even without the researcher's prior interest in the topic. The reflexive diary was thus used to delineate clear boundaries between teacher and researcher roles, and as far as possible prevent bias and represent all the data gathered. The raw data and the emergent themes were triangulated through discussion with the second author to ensure the ethics of transparency, quality, and reliability needed to ensure quality of qualitative research (Levitt et al. 2018). In addition, a transparent audit-trail, which grounded the themes and linked them back to the raw data, provided further methodological rigor and integrity.

\section{Results}

Four superordinate themes and associated subordinate themes were generated from the data. The superordinate themes were as follows: (1) Awareness of CFS patterns, (2) Group solidarity, (3) Mindfulness tools, and (4) Change and agency. The themes were highly interconnected and while they are presented here sequentially, they represent an organic development, which cooccurred as the course progressed. See Table 2 for superordinate and subordinate themes.

\section{Superordinate Theme: Awareness of CFS Patterns}

During the MBCT course, participants became aware of their cognitive patterns, which they were able to link to the etiological processes that precipitate and perpetuate CFS symptoms. This awareness seemed to be key in orchestrating change. As the course progressed, the participants became aware of four particularly prevalent habit patterns: a driven, perfectionist mode of being, a predisposition to guilt (strongly linked with people-pleasing), an awareness of substantial stress reactions, and a tendency to avoid their experiences. This theme explores how the participants' growing awareness allowed them to begin to develop insight into how these traits linked with their CFS symptomatology.

Table 2 Themes and sub-themes

\begin{tabular}{ll}
\hline Superordinate Themes & Subordinate themes \\
\hline 1.Awareness of CFS Patterns & 1.1 Constant driven-mode \\
& 1.2 Guilt as a driver \\
& 1.3 Strong stress reaction \\
2. Group solidarity & 1.4 Avoidance is not helpful \\
& 2.1 Mutual understanding \\
3. Mindfulness tools & 2.2 Learning from others \\
& 3.1 Breath as an anchor \\
4. Change and agency & 3.2 Everyday informal mindfulness \\
& 3.3 Developing mastery \\
& 4.1 Wider perspective \\
& 4.2 Change in self-dialog \\
& 4.3 Mindfulness helps emotional regulation \\
& 4.4 Permission for self-care \\
\end{tabular}


Subordinate Theme: Constant Driven-Mode Some participants became aware of their "driven-mode": for example, trying too hard, pushing themselves, and creating extremely high standards. Beth recognized this in herself and in others in the group: "We all seem to have a trait where we maybe over-work ourselves and that's helped to put us where we are now." As the course progressed participants realized how this driven-mode might have propelled their CFS. "I give $110 \%$. I would just keep pushing and pushing myself and then I end up 'out the bit' for three days" (Flora).

This pattern is known as "boom and bust", which was one of the psycho-educational elements taught during the course, a swinging cycle of high energy use, with strong inclination to push oneself, followed by days of paralyzing fatigue. Kath recognized herself in this cycle:

I just keep going till I hit the wall. It's a cycle where I push myself and then I become ill and iller and I do not ever seem to learn from that. It absolutely exhausts me, then it takes a couple of days to recover and by the time I've recovered, I go back into it again.

For Beth, it was less about the quantity of what she was doing and more about the perfectionist, high-standard quality of it. Both participants identified the consequences that these CFS-linked character traits had on their energy levels. "I've got to keep going, it has to be done to completion and perfection even though I know I'm going to hit the wall."

Subordinate Theme: Guilt as a Driver Participants almost universally carried a strong sense of guilt, which acted as a powerful driving force behind the driven, perfectionist behavior: "The guilt pushes me to do all of these things. I should really say 'no, I'm not doing it"' (Beth). A strong desire to people-please, with over-concern for others' opinion, appeared to be an antecedent to the guilt. "That's maybe a personality trait with CFS. People expect us to push ourselves to keep somebody else happy, to stop them criticizing us. It's an inner-belief- look after other people" (Flora).

Others expressed confusion as to why they felt so driven to behave in this way: "I'm definitely a people-pleaser, but much as I know that, I'll still do things for people, there isn't any reason to-they're not grateful and I don't owe them anything" (Lynn). This overly developed sense of conscience seemed to be a habitual pattern, which, although initially unquestioned and unexplored by the participants, was gradually exposed during the MBCT course and allowed participants to examine their habits.

Subordinate Theme: Strong Stress Reactions Most participants reported quite extreme degrees of almost permanent stress, which was experienced as a state of high alert. As the MBCT course progressed, the participants developed an awareness of how often they overreacted to stressful events: "I get really anxious and panicky because I usually tend to make mountains out of molehills" (Emma). Carol explicitly recognized that she was generating much of the stress herself, rather than the cause being solely external circumstances:

It's amazing how you build things up in your mind. I had all this adrenaline going through my body, that's a warning sign. Was I, am I creating this stress that I don't really need?

An important part of the MBCT course is encouraging participants to cultivate a strong awareness of their somatic experience. Some participants developed a growing understanding 
of their own "signature" of stress. For Lynn, this was a powerful acknowledgement of the disconnection she had between her mind and body:

We drew a scary picture of this person, with all these physical stress-symptoms. I've been blocking so much out, that while I might recognize that I'm feeling anxious to the point of panic, I find it difficult to actually identify what the physical symptoms are.

For other people, the physicality of their reaction was very obvious. "I just start panicking, getting anxious and sweaty. For me its fight or flight, definitely and that's how I've lived for years through the illness" (Emma).

As the course progressed, participants began to recognize the connection between thoughts and the stress reaction in the body: "It's amazing how you build things up in your mind and it is a thought isn't it? Then your body reacts to that and you start getting anxious" (Carol). Beth recognized how stressful thoughts can influence the body: "Looking at the worst-case scenario can affect the way your body reacts. It has opened my eyes to the fact that I can help my condition if I can control my thoughts." Participants linked the degree of fatigue they were experiencing to their strong stress reaction. Hannah summed up her understanding: "Recognizing how your stressful thoughts can run away and are actually causing a bodily effect. The fatigue could actually be a product of that."

Subordinate Theme: Avoidance Is Not Helpful One of the key principals of MBCT training is a shift in orientation, encouraging a "turning towards" one's experience even if unwanted and unpleasant. The course enabled many participants to become aware of their strong tendency to avoid what was uncomfortable. Hannah acknowledged its link with CFS: "There is a certain denial going on of emotionally difficult stuff that is not being faced. You just push it down and it can manifest itself in fatigue."

A few of the group began to register the effort required to avoid physical pain, and with it, recognized that the drawback of this was not "hearing" the valuable data that the body was providing:

I spend so much time trying to block out and suppress pain that when you are asked to concentrate on different areas of the body and you have to acknowledge it, I realized I do not listen to what the body is telling me. (Lynn)

In many ways, avoidance was understandable given that "turning towards difficulty" as taught in an MBCT course, is a radical, counter-intuitive, and challenging strategy as Beth described:

Facing stuff that I know has been there and that I have to deal with. I suppose I've always been putting those things on the back burner. It was just a wee bit like opening a can of worms and looking inside, it was emotionally difficult.

Iain was conscious that he used humor to deflect emotions: "Rather than dealing with something emotionally intense, I'll superficially glance over it with something funny." Carol noticed that she used distraction, specifically designed to avoid thinking but also recognized how energy draining this approach was:

I've been running away from things. I keep busy. I keep doing things. So I found that the sitting still was a major thing because it made me think about things I've spent all my life not wanting to think about. I've wasted my energy trying to not acknowledge these things. 
The group became aware of the relationship between these four traits (driven-mode, guilt, heightened stress reaction, avoidance) and their CFS symptoms. The awareness and insight into these embedded energy-draining habit patterns was the first stage in enabling the shift in perspective needed to generate changes in them.

\section{Superordinate Theme: Group Solidarity}

The participants deeply appreciated the support provided by fellow participants in the group. Given the unique challenges of living with CFS, with its poorly de-lineated etiology, lack of credence, distressing physical symptoms, and ensuing social isolation, they were relieved to meet and feel accepted by others in similar circumstances. Second, the group enabled participants to recognize CFS-perpetuating habit patterns in themselves by first recognizing it in others. This "mirroring" enabled them to consider alternative viewpoints.

Subordinate Theme: Mutual Understanding Participants contrasted their sense of acceptance within the MBCT group with the lack of empathy from "outside" regarding their CFS. Emma said: "You don't really have anybody that understands the illness and the exhaustion and the fear and the panic." Within the specific vulnerabilities of the condition, the groupforum provided participants with a sense of commonality and immediate comprehension. "It is a relief. It's not till you come into the group, being amongst people that you don't need to explain yourself to. They just 'get you'. You could be yourself-you have no idea what that meant" (Carol). This experiential understanding of CFS resulted in a sympathetic rapport focused particularly around dealing with symptoms:

We empathized with each other. Out there in the big bad world you get uncomfortable. But when you are in a group with people that are all the same, it is OK, nobody thinks 'look at them lying on the floor', we just all went 'I know how you feel' so that made the difference. (Flora)

Many of the group had internalized outside criticism and reported doubting themselves about their experience of CFS. Hearing others voice similar experiences was both consoling and encouraging. Kath explained: "The big thing is hearing and knowing other people say things that you feel or experience. It's reassuring and I think that is a massive, massive plus." This mutual understanding counterbalanced the loneliness and isolation of CFS: "It was like a wee contained haven. It just makes you feel like you are not alone in the world."(Flora)

Subordinate Theme: Learning from Others Comradeship had the additional benefit of mutually supportive learning. Participants became aware that, by observing others, they were able to recognize their own similar habit patterns. Beth said: "You're realizing that they are just trying to do what you are doing, trying to find a way to live with it." Participants utilized each others experiences to enable change in relation to their personal challenges of CFS.

People's comments were things that we could all identify with, so around the circle we were sort of saying 'mmmm I do that' (laughs). You can identify that there's this common thing that people are doing and maybe work on those area in our lives. (Lynn)

Beth gained insight from seeing those in the group who accepted their CFS and this motivated her to try this for herself: 
I learned quite a lot from other people that had accepted it. I was looking at them and thinking "well, you know you've come to terms with it and getting on with your life." It made me realize that that's something that I had to do.

There were two other advantages of learning MBCT in a group. One was the possibility of meeting challenge with a lighter touch: "What was really nice was that we brought laughing to it, so out of the heart of the pain, the struggles and the difficulties we brought some humor."(Gillian). The other was the supportive atmosphere of kindness and care: "The group was coming to an end and in the big wide world you won't have that gentleness and care."(Carol)

Kath beautifully summarized the particular benefits of being part of a group for people with CFS, both in terms of the solidarity, support and symbiotic learning: "If you try and do things on your own sometimes you'll go the wrong way. You just need the group to guide you back in."

\section{Superordinate Theme: Mindfulness Tools}

The participants' growing awareness, supported by the group process, led to shifts in thoughts and habit patterns that positively influenced their experience of CFS. The MBCT course content provided practical "tools" to aid these changes. These included: working with the breath, everyday mindfulness, and cultivating a sense of mastery. The participants found these practical elements very supportive: "We were given tools within the course that you can use for what is challenging and new and it can be as simple as using the breathing techniques." (Emma)

Subordinate Theme: Breath as an Anchor The participants reported bringing attention to the breath as a vehicle to enable emotional regulation. This generated a sense of stability and steadiness, described as "centering" by Emma: "You can really slow your breathing and the thoughts down. I kind of centre and breathe my way through things (laughs)." Paying deliberate attention to the breath also helped many of the group feel calmer. Although MBCT training suggests allowing the breath to be "just as it is", many participants found deliberate deep breathing was helpful:

I wear a wee ring that said 'just breathe' and everyone laughed 'of course you have to breathe, but I did not mean normal breathing-I mean taking the time to do deep breathing. It calms me down when the world is rushing towards my head. (Flora)

Participants often said they experienced their body in a high state of stress and alert, with a frequent description of being "speeded up." Beth reported that engaging in a breath practice enabled the "speediness" to reduce: "Taking that few minutes out to just breathe and stop your crazy mind for a wee while. You can just slow down a wee bit-I never did anything like that before. I just kept going."

Lastly, participants found that focus on the breath supported a shift to a more de-centered, observational position, Gillian said: "If I get agitated and stressed, I concentrate on breathing and if I take time and step back, I can sort of stop it and calm it down before it gets out of hand."

Given the propensity for stress in this population both as a precipitating factor in CFS and the distressing nature of its daily experience, participants reported that the breath practices 
which helped ground, calm, slow, and disentangle were very beneficial in working with the challenges of the condition.

Subordinate Theme: Everyday, Informal Mindfulness Although some participants found the formal meditation supportive in providing space and rest, given the nature of CFS, many found the formal 40-min and even the shorter 20-min practices frustrating, and said they almost immediately fell asleep. "I often found myself falling asleep during the practice and then I had missed a lot of and I felt quite badly about that" (Lynn). Some also regarded the formal practices as a chore to be got through. In contrast, practicing informal or "everyday" mindfulness, as a tool, was more easily incorporated into their day. "I try to be aware of what I'm doing now, even cooking and stuff, so that's a wee bit easier for me than actually just sitting down and doing the body scan." (Beth)

For many, when mindfulness was applied to everyday tasks, there was a sense of stepping into "being-mode":

Those wee triggers [everyday activities], reminds me to practice. It totally changed my perspective. It's not like adding an extra thing you have to do, it's that we are trying to be mindful most of the time. It's just a moment that I focus more on, enjoy this moment differently. (Hannah)

For Gillian, bringing awareness to those activities she could do, rather than focusing on what she could not, increased her sense of acceptance of her condition: "I might not be doing anything I consider worthwhile or useful but at least I'm enjoying that time sort of being present for whatever is happening and not wishing that things were different." Lynn said: "If I do even just a wee bit of mindfulness every single day, that keeps you in the habit of doing it. Just being more aware of everything, experiencing what's going on rather than just doing things automatically." Interestingly Flora found that the more she practiced everyday mindfulness, the more it became a default-mode of being rather than something she deliberately did: "Sometimes I'm not even consciously doing mindfulness, I just find myself doing it."

Subordinate Theme: Developing Mastery Mastery, here defined as a sense of achievement with what one has accomplished, is taught in week seven of the MBCT course. Given the frequent sense of incapacity people with CFS experience, several participants found developing a sense of mastery especially useful. Lynn, whose CFS was very limiting, found mastery a particularly helpful mode in which to view her experience:

I think an important point I took away was this idea of gaining a kind of mastery over difficulties and how you can use that as a kind of tool, an element of control of your attitude even if everything else is stripped away.

For Gillian, with the deliberate cultivation of self-appreciation, daily living was more manageable when her CFS was particularly challenging:

I sort of congratulate myself for the things that people generally would not think to, "well I did this today and I did that today." I've gotten quite good at recognizing when something is an achievement rather than downplaying it. I'm feeling a bit less hopeless than usual.

Flora had a humorful take on mastery, applying it to her everyday tasks: "I don't do a 'to-do' list anymore, I do a 'have-done' list - much better." The versatile use of the breath to aide 
emotional regulation, the simplicity and practicality of engaging in everyday mindfulness and applying a sense of mastery to the limitations of their functionality seemed to be tools that had potential value in helping them manage their CFS.

\section{Superordinate Theme: Change and Agency}

Participants, having cultivated awareness of CFS-perpetuating habit patterns through their own practice and application of mindfulness skills, gradually shifted into a process of change. These changes were experienced as a new sense of influence and control over their lives, explored here in five sub-themes: wider perspective, change in self-dialog, emotional regulation, permission for self-care, and acceptance.

Subordinate Theme: Wider Perspective Participants described fundamental shifts in regard to many aspects of their experience: their cognition, behavioral patterns, and attitude to selfcare. Carol described this:

It kind of opened up my brain space. I was just looking at everything all wrong. I was still trying to be the person I was before, so it was like "right push-on, do this do that." At the end [of the course] I've changed my mindset, life is different.

Others became increasingly aware of unhelpful striving, driven habit patterns which tended to perpetuate the energy-depleting nature of CFS. This enabled them to radically change their behavior-patterns, as Gillian described: "I mean I want to live in a clean house but there is always another day to do it or someone else to help you-its not the be-all and end-all I was treating it as." For Hannah, the shift enabled a loosening of a perfectionist rigidity, typical of many people with CFS: "It is actually OK to take your time and do things a bit more slowlynot try to be on top of all the things all the time."

Participants also began to perceive their bodies differently in the midst of physical discomfort. "Turning towards" their physicality countered a tendency to either avoid or negatively elaborate their physical experience Flora said: "I always thought I just exist here (points to head) but now I've extended down to here (points to torso)."

Lynn described how paying attention to her symptoms enabled her to be more deeply in touch with what was going on in her body: "It makes more sense now 'the body is a barometer of the mind' so you can use the body scan to listen to what your body's telling you." For some participants, the wider perspective related to a new-found nurturing and self-care, typically poor in people with CFS: "I jumped on my bicycle which was a foolish thing to do when you have CFS but I felt really good afterwards. Sometimes even if they cost energy they nurture and that changed my perspective" (Iain). This wider viewpoint of thoughts, habit patterns, and connection with their bodies, enabled the participants to relate differently, in a more open, appreciative, enquiring, and accepting mode, towards their experience of CFS.

Beth became aware of the need to change aspects of her "driven-mode," that were proving detrimental to her wellbeing:

I've got to keep going with very hard tasks till they are finished to perfection. There's a bit of me thinking, 'what would happen if I didn't do that?' The only person not benefitting is me. The mindfulness has got me aware of changes I've got to make. I did not quite realize the connection between always trying to be on top of things and the fatigue. 
Flora found that changing her relationship to her stressful thoughts profoundly affected her ability to cope with her life:

Stressful thoughts just pop in, we canny help them but you can quiet down your brain and then it is not so tired and its easier to cope with everything, so that was quite epic. It just shows you, it's changing my thinking.

Cathy realized much of her exhaustion stemmed from a restless need to keep busy in order to avoid a bombardment of thoughts. Once she understood this, she was able to change her relationship to thoughts:

I could not get away from my thoughts but I've learned to stop fearing them and maybe that's going to help. I've been letting them come in and go out again rather than trying to block them, so I do not need to keep busy, busy, busy. It can manifest itself in fatigue.

Awareness of unskillful habit patterns and how these contributed to their CFS enabled a shift in attitude and behavioral patterning that were less energy depleting and more self-caring. This seemed to free-up energy previously spent maintaining old unhelpful traits.

Subordinate Theme: Change in Self-Dialog Many participants became aware of their strong, self-critical thoughts, and how these could powerfully affect how they felt. They noticed how the strength and influence of this "inner-voice" could be harnessed in a more positive way. With their new-found orientation towards self-care, they began to cultivate more helpful thoughts. Beth described this in relation to her work:

In a stressful situation, I'll say to myself, 'wait a wee minute, that hasn't actually happened yet, this is a thought' and it does make me reduce the stress levels, so absolutely, it has made a big difference.

Participants recognized a tendency to catastrophize, with its resultant physical stress reaction, and to counter this process described applying an alternative narrative: "When things are stressful, I'll say to myself, 'no wait a minute, you're building that up and getting all sweaty and anxious'." (Kath)

Two participants made use of their internal dialog to prompt themselves to be aware of their relationship to thoughts: "So long as I can remember to remind myself 'don't think that way', I'm OK." (Lynn) and: 'Take time to think and say to myself, 'OK, those thoughts are there but that's OK'." (Emma)

Others used internal dialog as a reminder to self-care. Flora, who was particularly prone to pushing herself, despite obvious detrimental effects on her body, used her self-narrative firstly to step out of the auto-pilot of striving: "I'll say-'actually today I'm too sore to do that', whereas before I would just have pushed myself to do it" and secondly to deliberately build in a voice of self-kindness: "I tell myself 'no, if you don't feel like doing that, don't -have a wee seat, have a wee mindfulness moment'." Emma recognized how easy it was to be carried away by a stream of thoughts and had found a way to hold herself steady:

I do not go off on a tangent. I recognized those thoughts and fears were there but I had a way of working through it this time, just that little tweak of thoughts. It's not mindblowing, its just turning a notch and looking at it a different way.

Subordinate Theme: Mindfulness Helps Emotional Regulation The participants noticed benefits of increased emotional regulation. Hannah spoke of how a change in her relationship 
to stress freed up energy: "Just knowing that the stress wasn't helping. It was actually taking energy away from me, so I just decided not to do it (laughs)."

Others found that recognizing and working skillfully with stress had the effect of reducing pain and fatigue:

When I get stressed, I get tenser and sorer and tireder. It is a vicious circle. To be able to break that circle makes everything more manageable. The mindfulness just calmed and slowed me right down and then, if I do not get all stressed and tensed up and sore it links into helping my chronic fatigue. Who needs alcohol when you have got meditation? (Flora)

Having the awareness to notice the stress response early in its genesis allowed Gillian to catch the frustration and de-escalate her agitation:

CFS is frustrating. If I can recognize when I'm getting upset and I'm not sort of too far into it, I can stop it in its tracks. If I can take a few minutes to concentrate on breathing and take a step back, I can sort of stop it and calm it down rather than it get out of hand.

Beth also found that emotional regulation positively influenced her condition:

I've been aware of how stressful situations and my emotions could sometimes make me worse. You have all these scenarios-'Oh god! what if...' so I'm very aware how my thoughts can make my body react and I'm stopping myself doing that. I'm calmer, I can bring myself down again and I control my condition better.

Emotional regulation, particularly in relation to the physical strain of the stress response, seemed to be especially useful for participants. The "self-soothing" afforded by the mindfulness training preserved and freed up energy resources.

Subordinate Theme: Permission for Self-Care The development of self-kindness and gentleness was at first an alien concept for participants. For many, there seemed to be a sense of requiring permission for self-care. This "permission" was provided by the orientation towards self-compassion in MBCT course: "My body is knackered and it was like 'ohhh god! somebody is actually saying I'm allowed to lie down' which is really what we usually don't do - you just keep going (laughs)" (Flora).

Mindfulness training encourages tuning into the body and its sensations, which have often been ignored, thus enabling a recognition for a need for self-care and resting: "I need to start listening to what my body is telling me. I didn't know that before. I had loads of signs 'cos my body has obviously told me 'no you can't, you need to stop, sit still'." (Lynn)

This new awareness of her body allowed Hannah to directly and radically generate compassion towards her experience of pain: "If I'm doing a body scan and its sore I think, 'right, lets send some heat', 'give it some love'. I know we don't, but in my head I do. I send some heat and be gentle with it."

There had been discussion within the class of the "boom and bust cycle", a tendency to push themselves despite obvious lack of energy into an inevitable crash of fatigue. For many of the group there was a shift into "letting themselves off the hook" and countering CFS tendencies to push and strive which was expressed as a form of improved self-care: "The recovery is maybe coming quicker at times. I have noticed I can't go 'boom boom boom', so now I just pick 'boom"' (Cathy). Flora likened this shift from striving, to identifying a need to rest as a form of "body-hygiene," as in looking after herself. 
Before I would have just kept pushing and pushing and now I go 'no I need to go to my bed'; or 'need to have a rest' or - get this -'I need to go and practice-my body needs a body scan' (laughs). Its body-hygiene.

For Emma, this concept of license to self-care was particularly strong:

Probably its taking time-out, giving yourself permission, that its actually OK to be kind to yourself and how that has a huge impact on your physical and mental condition when you do not do that. So you know 'I am worthy', 'I deserve to be kind to myself'. Just to stop, go a wee bit slower really empowered me. It gives you permission, it gives you control.

Beth echoed this saying: "I think it's all about that gentleness to myself, that kindness and caring and understanding that you show to other people."

The encouragement to "listen" to the body, and the orientation towards self-compassion taught during the course as well as the kindness generated between the participants within the class, enabled a shift towards increased body awareness, transformation from striving to kinder habit patterns, and a sense of permission for self-care afforded in part by a recognition of the need to "treat thyself as you treat others".

Subordinate Theme: Greater Acceptance Given the nature of CFS, with its chronicity and lack of ameliorating treatment, a shift from an agenda of "eradication" to one of "acceptance" was a key modality that enabled participants to acknowledge the reality of their CFS. Beth described this concept: "I hadn't really thought about living with it, I'd just thought about getting rid of it. OK you've got it. It's acceptance and realizing you can have a reasonable quality of life- 'it is what it is'." Lynne explained her acceptance of the reality of her life while holding a desire to return to previous functioning:

I think that if you are going to progress, you have to recognize and start from where you are now, rather than where you wish you were or where you used to be. I could see the importance of that-just acknowledging how it is.

Carol took this concept of acceptance one step further and spoke of how returning to the attitude she had before CFS may actually be detrimental rather than desirable:

Well the way I've been trying to work it hasnae worked. I just have to plod on and look to my mindset to be different. So that's where my headspace is now. I think, instead of harking back to what I used to do, I realize that's what got me here in the first place. There might be a better way forward (laughs).

The shift into acceptance of the actuality of CFS was different among participants. For some it was a sense of letting go of their past "healthy" self, others changed their attitude towards the reality of their current experience. For others still, recognizing how old patterns had had a part to play in the origin of their CFS helped adaptation into a sense of "new-self."

\section{Discussion}

During the course, participants described how they became aware of specific vulnerabilities that are particular to CFS, and with the support of the group and specific mindfulness tools, 
reported a change in habit patterns which maintain and perpetuate CFS, such as perfectionism, being driven, people-pleasing, and tendency to catastrophize. There were three very specific transformative changes that occurred as a result of the MBCT course, which were supported across the four superordinate themes. These were the development of acceptance, a cultivation of self-care, and a reduction in heightened stress reaction.

\section{Development of Acceptance}

Given the chronic, unpredictable nature of CFS and the lack of curative treatment, cultivating a stance of acceptance of "what is," shifted the participants' agenda from a goal of "getting rid" of their condition to working skillfully with it. Crane (2008) describes the goal-driven "doing" mode as being cognitively focused and future orientated. This creates a tendency to discrepancy monitor, that is, monitoring the mismatch between where one actually is and the goal of where one wants to be (Bishop et al. 2004; Segal et al. 2013). The participants developed awareness that this striving to close the gap of how they found themselves and how they wished themselves to be, often demanded large amounts of draining energy.

The shift to acceptance, as a valid mode of coping with CFS, was enhanced by the mutual, supportive learning environment of the class. For some participants, acceptance involved acknowledging the fundamental truth of their current disability. For others, it was a recognition of the impossibility of meeting previous high standards and a welcome letting go of the exhausting maintenance of habit patterns. After the course, participants recognized that these patterns such as perfectionism, people pleasing, and feeling guilty were not only counterproductive but also potentially instrumental in the etiology of their condition (Hambrook et al. 2011; Luyten et al. 2011; Van Houdenhove and Luyten 2008).

\section{Cultivation of Self-Care}

The extant research which explores MBPs for CFS populations reported significant shifts in self-reported measures of anxiety, somatization, and unhelpful cognitions and behaviors (Rimes and Wingrove 2013; Sampalli et al. 2009; Surawy et al. 2005). However only the latter of these studies measured and reported improvement in self-compassion scores (Neff 2003). This study showed that increased self-care and self-compassion were fundamental to the shift participants experienced in managing their CFS.

This shift to enhanced self-kindness appeared to arise from a willingness to step out of the driven, energy-draining personality traits of perfectionism, high standards, conscientious, driven working style, and a strong susceptibility to self-criticism (Hambrook et al. 2011; Luyten et al. 2011). The mechanisms by which the mindfulness training enabled this shift appeared to be threefold. First, there was an increased awareness and an intention to "listen" to symptoms rather than ignore them. This led to a more gentle, kindly, and forgiving attitude towards their bodies experiencing fatigue and pain. Second, the participants developed metacognitive awareness (Bishop et al. 2004; Teasdale 1999), allowing them to observe their thought processes more clearly. This allowed them to recognize the critical, driven nature of their self-narrative and enabled them to create a kinder less judgmental inner-dialog. Third, the kindness and care developed within the group acted as a medium in which a "permission to self-care" was cultivated. This permission frequently translated into a license to rest, previously un-granted because striving and pushing was so ingrained and prevalent. This shift frequently resulted in protection and preservation and replenishing of limited energy. 


\section{Reduction in Stress Reaction}

As the course progressed, many participants became aware of an exaggerated stress response, felt physically in the body as pain and fatigue, emotionally as anxiety, and cognitively as fast, racing thoughts. This awareness led participants to actively apply mindfulness to reduce their stress response. First, they found the breath gave them a sense of grounding, calming, stepping back, and providing rest from stressful experiences and reactions. Second, they found everyday mindfulness allowed them to shift attention from catastrophizing thoughts, which would inevitably generate a high stress response onto the more neutral actuality of what they were doing in that moment. Third, they developed a self-soothing inner-dialog that encouraged them to move attention to the breath, remember that thoughts are not facts, and recognize that there may be a habitually exaggerated response going on that they could disengage from. As a result, many of the group reported a reduction in pain and fatigue.

This is supported by previous literature. For example, Teper et al. (2013) found that mindfulness training improved executive control and enhanced emotional regulation by allowing attention to be more deliberately held or shifted. Hölzel et al. (2009) found reduced amygdala size after participants had attended a MBSR course, the reduction in size of this "emotional center" of the brain likely being due, in part, to participants being able to shift attention away from stressful negative thoughts.

\section{Limitations and Future Research}

This study was based on the experience of nine participants and is thus not intended to be generalizable, but is an in-depth exploration of individual experience. Despite research pointing towards typical character traits common in people with CFS (Van Houdenhove and Luyten 2008), it is vitally important that each individual's experience of CFS and how mindfulness training impacts on them be acknowledged as unique and personal. However, the broad shifts in cognition, attitude, and self-care were common among participants, which points towards shared mechanisms of change and a more de-centered approach to their experience, which maps onto the theoretical work on mechanisms of mindfulness (Shapiro et al. 2006).

There was just one male participant, so the group discussions and the learning from the group process was female orientated. Different learning and therefore themes may have emerged from a more male-based perspective on the experience of CFS, had there been a greater gender balance. Finally, three of the original twelve participants dropped out, two after the first week. Only the data from those who completed the course was used in this study and so inevitably the findings are limited to those for whom mindfulness training proved to be helpful. Further research exploring why participants drop out would be useful in terms of making potential modifications to the course to make it as accessible as possible, for example offering online MBCT courses to those severely affected by fatigue may increase accessibility.

This study specifically focused on how an adapted MBCT affects people with CFS. In future a mixed research model may gather both more extensive insight into the experiences of people with CFS attending an MBCT course while simultaneously exploring its efficacy with quantitative data. For instance, this could be explored by linking the mechanisms of how mindfulness training enabled energy to be preserved with a fatigue outcome measure, such as the Chalder Fatigue Scale (Chalder et al. 1993). Alternatively, investigating more deeply the mode in which self-compassion and self-care impact on the experience of CFS could be matched with self-compassion scale measures (Neff 2003). 
Availability of Data and Material n/a

Authors' Contributions First author: Led the study design, data collection, thematic analysis, and wrote the article. Second author: Was the academic thesis supervisor, contributed to the design, writing, and editing of the study, and triangulated the thematic analysis.

Funding Information This study was internally funded.

\section{Compliance with Ethical Standards}

Conflict of Interest Mindfulness-Based Cognitive Therapy was lightly adapted and delivered by the first author for the purposes of this study, and both authors are trained to teach Mindfulness-based Programmes.

Ethics Approval This study was approved by a University ethics committee and is therefore in accordance with the ethical standards laid down in the 1964 Declaration of Helsinki. All participants gave informed consents prior to their inclusion in the study.

Consent to Participate All participants gave their informed consent to participate.

Consent for Publication All participants gave their informed consent for their data to be published.

Open Access This article is licensed under a Creative Commons Attribution 4.0 International License, which permits use, sharing, adaptation, distribution and reproduction in any medium or format, as long as you give appropriate credit to the original author(s) and the source, provide a link to the Creative Commons licence, and indicate if changes were made. The images or other third party material in this article are included in the article's Creative Commons licence, unless indicated otherwise in a credit line to the material. If material is not included in the article's Creative Commons licence and your intended use is not permitted by statutory regulation or exceeds the permitted use, you will need to obtain permission directly from the copyright holder. To view a copy of this licence, visit http://creativecommons.org/licenses/by/4.0/.

\section{References}

Asbring, P. (2001). Chronic illness-a disruption in life: identity-transformation among women with chronic fatigue syndrome and fibromyalgia. Journal of Advanced Nursing, 34, 312-319.

Åsbring, P., \& Närvänen, A. L. (2002). Women's experiences of stigma in relation to chronic fatigue syndrome and fibromyalgia. Qualitative health research, 12(2), 148-160.

Bishop, S. R., Lau, M., Shapiro, S., Carlson, L., Anderson, N. D., Carmody, J., \& Devins, G. (2004). Mindfulness: a proposed operational definition. Clinical Psychology: Science and Practice, 11, 230-241.

Braun, V., \& Clarke, V. (2006). Using thematic analysis in psychology. Qualitative Research in Psychology, 3, 77-101.

Braun, V., \& Clarke, V. (2013). Successful qualitative research: a practical guide for beginners. Sage.

Carruthers, B. M., Jain, A. K., De Meirleir, K. L., Peterson, D. L., Klimas, N. G., Lerner, A. M., \& Sherkey, J. A. (2003). Myalgic encephalomyelitis/chronic fatigue syndrome: clinical working case definition, diagnostic and treatment protocols. Journal of Chronic Fatigue Syndrome, 11, 7-115.

Centers for Disease Control and Prevention. (2014). Myalgic Encephalomyelitis/Chronic Fatigue Syndrome. Retrieved from https://www.cdc.gov/me-cfs/index.html.

Chalder, T., Berelowitz, G., Pawlikowska, T., Watts, L., Wessely, S., Wright, D., \& Wallace, E. P. (1993). Development of a fatigue scale. Journal of Psychosomatic Research, 37, 147-153.

Chambers, D., Bagnall, A. M., Hempel, S., \& Forbes, C. (2006). Interventions for the treatment, management and rehabilitation of patients with chronic fatigue syndrome/myalgic encephalomyelitis: an updated systematic review. Journal of the Royal Society of Medicine, 99, 506-520.

Chew-Graham, C., Dowrick, C., Wearden, A., Richardson, V., \& Peters, S. (2010). Making the diagnosis of chronic fatigue syndrome/Myalgic encephalitis in primary care: a qualitative study. BMC Family Practice, 11, 16.

Clements, A., Sharpe, M., Simkin, S., Borrill, J., \& Hawton, K. (1997). Chronic fatigue syndrome: a qualitative investigation of patients' beliefs about the illness. Journal of Psychosomatic Research, 42, 615-624. 
Crane, R. (2008). Mindfulness-based cognitive therapy: Distinctive features. London: Routledge.

Crane, R. S., Eames, C., Kuyken, W., Hastings, R. P., Williams, J. M. G., Bartley, T., Evans, A., Silverton, S., Soulsby, J. G., \& Surawy, C. (2013). Development and validation of the mindfulness-based interventionsteaching assessment criteria (MBI: TAC). Assessment, 20, 681-688.

Crane, R. S., Brewer, J., Feldman, C., Kabat-Zinn, J., Santorelli, S., Williams, J. M. G., \& Kuyken, W. (2017). What defines mindfulness-based programs? The warp and the weft. Psychological Medicine, 47, 990-999.

Dickson, A., Knussen, C., \& Flowers, P. (2008). 'That was my old life; it’s almost like a past-life now': Identity crisis, loss and adjustment amongst people living with chronic fatigue syndrome. Psychology and Health, 23, 459-476.

Fukuda, K., Straus, S. E., Hickie, I., Sharpe, M. C., Dobbins, J. G., \& Komaroff, A. (1994). The chronic fatigue syndrome: a comprehensive approach to its definition and study. Annals of Internal Medicine, 121, 953-959.

Griffith, G. M., Bartley, T., \& Crane, R. S. (2019). The inside out group model: teaching groups in mindfulnessbased programs. Mindfulness, 10(7), 1315-1327.

Hambrook, D., Oldershaw, A., Rimes, K., Schmidt, U., Tchanturia, K., Treasure, J., \& Chalder, T. (2011). Emotional expression, self-silencing, and distress tolerance in anorexia nervosa and chronic fatigue syndrome. British Journal of Clinical Psychology, 50, 310-325.

Heijmans, M. J. (1998). Coping and adaptive outcome in chronic fatigue syndrome: importance of illness cognitions. Journal of Psychosomatic Research, 45, 39-51.

Hölzel, B. K., Carmody, J., Evans, K. C., Hoge, E. A., Dusek, J. A., Morgan, L., \& Lazar, S. W. (2009). Stress reduction correlates with structural changes in the amygdala. Social Cognitive and Affective Neuroscience, 5, 11-17.

Kabat-Zinn, J. (1982). An outpatient program in behavioral medicine for chronic pain patients based on the practice of mindfulness meditation: theoretical considerations and preliminary results. General Hospital Psychiatry, 4, $33-47$.

Knoop, H., Bleijenberg, G., Gielissen, M. F., van der Meer, J. W., \& White, P. D. (2007). Is a full recovery possible after cognitive behavioral therapy for chronic fatigue syndrome? Psychotherapy and Psychosomatics, 76, 171-176.

Larun, L., \& Malterud, K. (2007). Identity and coping experiences in chronic fatigue syndrome: a synthesis of qualitative studies. Patient Education and Counseling, 69, 20-28.

Levitt, H. M., Bamberg, M., Creswell, J. W., Frost, D. M., Josselson, R., \& Suárez-Orozco, C. (2018). Journal article reporting standards for qualitative primary, qualitative meta-analytic, and mixed methods research in psychology: the APA Publications and Communications Board task force report. American Psychologist, 73, 26.

Luyten, P., Kempke, S., Van Wambeke, P., Claes, S., Blatt, S. J., \& Van Houdenhove, B. (2011). Self-critical perfectionism, stress generation, and stress sensitivity in patients with chronic fatigue syndrome: relationship with severity of depression. Psychiatry: Interpersonal and Biological Processes, 74, 21-30.

Moss-Morris, R., \& Chalder, T. (2003). Illness perceptions and levels of disabilityin patients with chronic fatigue syndrome and rheumatoid arthritis. Journal of Psychosomatic Research, 55, 305-308.

Moss-Morris, R., Sharon, C., Tobin, R., \& Baldi, J. C. (2005). A randomised controlled graded exercise trial for chronic fatigue syndrome: outcomes and mechanisms of change. Journal of Health Psychology, 10(2), 245-259.

Neff, K. D. (2003). The development and validation of a scale to measure self- compassion. Self and Identity, 2 , 223-250.

Rimes, K. A., \& Wingrove, J. (2013). Mindfulness-based cognitive therapy for people with chronic fatigue syndrome still experiencing excessive fatigue after cognitive behavior therapy: a pilot randomized study. Clinical Psychology \& Psychotherapy, 20, 107-117.

Sampalli, T., Berlasso, E., Fox, R., \& Petter, M. (2009). A controlled study of the effect of a mindfulness-based stress reduction technique in women with multiple chemical sensitivity, chronic fatigue syndrome, and fibromyalgia. Journal of Multidisciplinary Healthcare, 2, 53.

Segal, Z. V., Williams, J. M. G., \& Teasdale, J. D. (2013). Mindfulness-based cognitive therapy for depression. New York: Guilford Press.

Shapiro, S. L., Carlson, L. E., Astin, J. A., \& Freedman, B. (2006). Mechanisms of mindfulness. Journal of Clinical Psychology, 62, 373-386.

Sharpe, M., Hawton, K., Simkin, S., Surawy, C., Hackmann, A., Klimes, I., \& Seagroatt, V. (1996). Cognitive behaviour therapy for the chronic fatigue syndrome: a randomised controlled trial. British Medical Journal, 312, 22-26.

Surawy, C., Hackmann, A., Hawton, K., \& Sharpe, M. (1995). Chronic fatigue syndrome: a cognitive approach. Behavior Research and Therapy, 33, 535-544.

Surawy, C., Roberts, J., \& Silver, A. (2005). The effect of mindfulness training on mood and measures of fatigue, activity, and quality of life in patients with chronic fatigue syndrome on a hospital waiting list: a series of exploratory studies. Behavioral and Cognitive Psychotherapy, 33, 103-109.

Teasdale, J. D. (1999). Metacognition, mindfulness and the modification of mood disorders. Clinical Psychology and Psychotherapy, 6, 146-155.

Teper, R., Segal, Z. V., \& Inzlicht, M. (2013). Inside the mindful mind: How mindfulness enhances emotion regulation through improvements in executive control. Current Directions in Psychological Science, 22, 449-454. 
Van Houdenhove, B., \& Luyten, P. (2008). Customizing treatment of chronic fatigue syndrome and fibromyalgia: the role of perpetuating factors. Psychosomatics, 49, 470-477.

Whitaker, R. C., Herman, A. N., Dearth-Wesley, T., Hubbell, K., Huff, R., Heneghan, L. J., \& Rowe, P. C. (2019). The association of fatigue with dispositional mindfulness: relationships by levels of depressive symptoms, sleep quality, childhood adversity, and chronic medical conditions. Preventive Medicine, 129, 105873.

Whitehead, L. (2006). Toward a trajectory of identity reconstruction in chronic fatigue syndrome/myalgic encephalomyelitis: a longitudinal qualitative study. International Journal of Nursing Studies, 43, 1023-1031.

Wiborg, J. F., Knoop, H., Stulemeijer, M., Prins, J. B., \& Bleijenberg, G. (2010). How does cognitive behaviour therapy reduce fatigue in patients with chronic fatigue syndrome? The role of physical activity. Psychological Medicine, 40, 1281-1287.

Willig, C. (2013). Introducing qualitative research in psychology. McGraw-hill education (UK).

Publisher's Note Springer Nature remains neutral with regard to jurisdictional claims in published maps and institutional affiliations. 